\title{
ESPAÇO GEOGRÁFICO E CIRCUITO INFERIOR DA ECONOMIA URBANA
}

\author{
geographic space and lower circuit of the urban economy
}

Diego Salomão Candido de Oliveira Salvador *

\begin{abstract}
Resumo
No presente trabalho, objetivamos compreender a cidade dos países subdesenvolvidos como um espaço banal, atentando para a expansão e a redefinição do circuito inferior da economia urbana no período atual. Para isso, organizamos o texto em três partes. Na primeira, tecemos reflexões sobre o espaço geográfico como sinônimo de espaço banal, noção que explicita que a realidade é marcada pela coexistência desigual e contraditória de todos os agentes sociais (hegemônicos e não hegemônicos) e de todas as atividades econômicas (superiores e inferiores). Na segunda, trazemos à tona o espaço banal da cidade dos países subdesenvolvidos, considerando a importância da teoria dos dois circuitos da economia, formulada por Milton Santos, no final da década de 1970, para a análise da dinâmica dessa cidade. Discutimos também a expansão e a redefinição do circuito inferior no período atual, tendo como exemplo empírico o território do Rio Grande do Norte, estado da região Nordeste do Brasil. Na terceira, fazemos consideracões finais, ratificando a necessidade de se estudar a dinâmica socioespacial da cidade dos países subdesenvolvidos considerando a totalidade dessa dinâmica, isto é, atentando para a coexistência do circuito superior e do circuito inferior nesse espaço. Assim sendo, concluímos ser pertinente considerar a teoria dos dois circuitos da economia urbana, analisando a dinâmica desses circuitos de acordo com as variáveis-chave que marcam o contexto atual do capitalismo.
\end{abstract}

Palavras-chaves:Cidade dos países subdesenvolvidos, Circuitos da economia urbana, Espaço banal.

\section{Abstract}

In this work, we objective to understand the city of underdeveloped countries as a common place, paying attention for expansion and redefinition of the lower circuit of urban economy in the current period. Then, we articulate the text into three parts: in the first, we made reflections about the geographical space as a synonym of common place, which spells out that the reality is marked by unequal and contradictory coexistence of all social actors (non-hegemonic and hegemonic) and of all economic activities (upper and lower); in the second, we bring to the city's common place of underdeveloped countries, considering the importance of the theory of two circuits of the economy, formulated by Milton Santos in 1970, for the analysis of the dynamics of that city and discussing the expansion and redefinition of the lower circuit in the current period, taking as an example the empirical realm of Rio Grande do Norte, in the northeastern region of Brazil; and in the third, we perform the final considerations, by ratifying the need to study the socio-spatial dynamics of city of underdeveloped countries considering the totality of this dynamic, in other words, by paying attention to the coexistence of the upper circuit and the lower circuit in this space. Thus, we say be relevant considering the theory of two circuits of the urban economy, analyzing the dynamics of these circuits according to the key variables that mark the current context of capitalism.

Key words: City of underdeveloped countries, Circuits of the urban economy, Common place.

\section{Résumé}

Dans ce travail, nous engageons à comprendre la ville des pays sous-développés comme un espace public, avec atention pour l'expansion et la redéfinition du circuit inferieur de l'économie urbaine dans la période actuelle. Pour ça, nous articulons le texte en trois parties: dans la première, nous faisons réflexions sur l'espace géographique comme synonyme d'espace public, qui énonce que cette réalité est marqué par la coexistence inégal et contradictoire de tous les acteurs sociaux (non hégémoniques et hégémoniques) et de toutes les activités économiques (supérieur et inférieur); dans la seconde, nous apportons à l'espace public de la ville des pays sous-développés, compte tenu de l'importance de la théorie des deux circuits de l'économie, formulée par Milton Santos à la fin des années 70, pour l'analyse la dynamique de cette ville et discuter l'expansion et la redéfinition du circuit inférieur dans la période actuelle, prenant comme exemple le domaine empirique du Rio Grande Norte, dans la région du nord-est du Brésil; et dans le troisième, nous effectuons les considérations finales, en ratifiant la nécessité d'étudier la dynamique socio-spatiales de ville de pays sous-développés, compte tenu de l'ensemble de cette dynamique, c'est-à-dire, en prêtant attention à la coexistence du circuit superieur et le circuit inférieur dans cet espace. Ainsi, nous dirons être pertinent compte tenu de la théorie des deux circuits de l'économie urbaine, pour analyse la dynamique de ces circuits selon les variables clés qui marquent le contexte actuel du capitalisme.

Mots-Clés: Ville de pays sous-développés, Circuits de l'économie urbaine, Espace public.

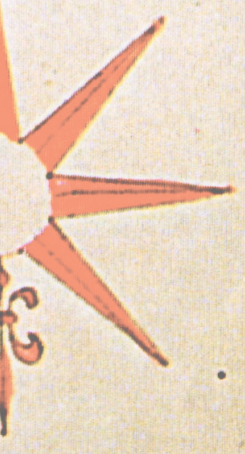

(*) Doutorando em Geografia pela Universidade Estadual de Campinas, Prof. Msc. do Departamento de Geografia da Universidade Federal do Rio Grande do Norte - CERES, Rua Joaquim Gregório, Penedo, CEP 59.300-000, Caicó (RN), Brasil. Tel: (+55 84) 34214870 - diegosalomao84@hotmail.com 


\section{INTRODUÇÃO}

O espaço geográfico, objeto de estudo que alicerça todas as reflexões no âmbito da ciência geográfica, é um híbrido de objetos e ações, e é constantemente alterado (SANTOS, 1996). Vale destacar que, no processo de produção do espaço, os objetos são, cada vez mais, utilizados pelos variados agentes sociais (hegemônicos e não hegemônicos), sob diferentes perspectivas: os hegemônicos os usam, geralmente, com a finalidade de exploração do espaço como um recurso, visando à geração de lucratividade; já os não hegemônicos os utilizam calcados na sobrevivência, considerando, assim, o espaço como um abrigo, onde buscam a geração da renda mensal e, assim, a possibilidade do consumo. Do mesmo modo, as ações que marcam o espaço produzido pelos homens são hegemônicas e não hegemônicas. É verdade que, no período atual, o Estado vem privilegiando as ações hegemônicas, o que não quer dizer que não existam ações de outro tipo.

Nessa perspectiva, todos os agentes sociais podem produzir espaço, logicamente de maneiras diferentes e expressando desiguais lucratividades e potencialidades para a competitividade deles entre si e com outros agentes. Assim, para compreendermos a globalização, que pode ser tomada como o estágio atual do sistema capitalista (SANTOS, 2003), em que há uma gestão global de múltiplas diferenciações espaciais (SOUZA, 2002), temos que atentar para as ações dos diferentes agentes sociais no processo de produção do espaço (HARVEY, 2004, 2005), o que nos possibilitará também a apreensão das desigualdades existentes entre esses agentes.

Vale destacar que, apesar de o espaço ser produzido de diferentes maneiras, o Estado tem privilegiado as ações das forças (ou agentes) hegemônicas no âmbito do sistema capitalista. $\mathrm{O}$ Estado, desse modo, comumente apresenta-se como mero coadjuvante, atuando, muitas vezes, como testemunha no processo de produção corporativa do espaço (SANTOS, 2007). Com isso, o espaço, sob o jogo de interesses individualistas e conflitantes dos agentes dominantes, acaba sendo produzido de acordo com a lógica das desigualdades, contradições e combinações, tornando-se, assim, fragmentado.

Todavia, o espaço não é produzido somente pelas grandes empresas (que sinalizam os interesses dos agentes hegemônicos) e pelo Estado, mas também pelas pequenas empresas (muitas das quais são representantes da economia popular) e pelos pobres, que buscam incansavelmente sua sobrevivência, revelando, em suas atividades, muita criatividade e outro tipo de organização, a qual difere da organização burocrática que caracteriza as grandes empresas (SANTOS, 1979).

Assim sendo, devido ao fato de o espaço ser produzido por todos os agentes sociais (hegemônicos e não hegemônicos) e por todas as atividades socioeconômicas (superiores e inferiores), ele revela a dinâmica do real e, destarte, por meio dele, podemos compreender a totalidade das relações que marcam tanto a dinâmica do espaço brasileiro como um todo quanto a dos variados subespaços que o constituem.

Contudo, para apreendermos essa totalidade temos que ter consciência de que o espaço é banal, isto é, permeado pelas ações de todos os agentes sociais e por todas as atividades econômicas desencadeadas por esses agentes, explicitando, assim, desigualdades e combinações no tocante às ações e aos anseios desses agentes e a suas respectivas atividades. Em outras palavras, concordamos com Santos (2009, p. 04), ao afirmar que

o espaço banal é o espaço de todos os homens, de todas as instituições, de todas as empresas. Destarte, quando trabalhamos com o espaço banal, trabalhamos com todo o espaço. O espaço banal é o espaço do geógrafo e as cidades se tornaram hoje espaço banal por excelência, porque nenhum outro subespaço mistura tanto os homens, as empresas, as instituições, que se criam, ás vezes, à revelia das instituições hegemônicas.

Portanto, "é importante enxergar a cidade [leia-se o espaço] sempre como uma totalidade, independentemente de seu tamanho ou localização" (ARROYO, 2008, p. 30). Isso pode ser feito, 
segundo a citada autora, de duas maneiras. Uma delas é atentando para os circuitos espaciais de produção, que são formados por empresas de diversos tamanhos e organizações, "[...] voltadas para um determinado bem ou serviço, e que atingem de forma articulada diferentes frações do território" (Ibid. p. 30). Há circuitos espaciais de produção dispersos no espaço, assim como há outros concentrados em determinados subespaços; do mesmo modo, há aqueles extrovertidos (vinculados, sobretudo, ao mercado externo) e aqueles não extrovertidos (Ibid.). Em suma, a escala geográfica de ação dos circuitos espaciais de produção revela uma organização do espaço e explicita o fato de o trabalho ser sempre comum, solidário e circular.

Outra maneira de nos aproximarmos da totalidade da dinâmica socioespacial é por meio da análise dos circuitos da economia urbana, "[...] que envolvem atividades e agentes com diferentes níveis de capital, trabalho, organização e tecnologia" (Ibid., p. 30), todas(os) coexistindo no espaço, de forma solidária e contraditória. Assim sendo, "os circuitos superior e inferior interagem e participam do movimento que se desenvolve dentro da mesma cidade: trata-se de um único meio construído, embora desigual e fragmentado, e de um único mercado, embora fortemente segmentado" (ARROYO, 2008, p. 30).

Destarte, coadunando Arroyo (2008), asseveramos que podemos compreender a totalidade socioespacial pela justaposição dos circuitos espaciais de produção (analisando, mais detalhadamente, os ramos de atividades econômicas) e dos circuitos da economia urbana (atentando mais para a coexistência de agentes socioeconômicos). O importante é sabermos que os circuitos da economia urbana sempre integram circuitos espaciais de produção, ou que aqueles são, eles mesmos, exemplos destes, já que, geralmente, envolvem todas as fases do processo produtivo (produção, distribuição, comercialização, consumo). Sendo assim, esses dois aspectos de análise estão justapostos, servindo para a compreensão da totalidade espacial. Neste trabalho, propomo-nos refletir, especificamente, sobre a importância dos circuitos da economia urbana para a apreensão do espaço banal da cidade dos países subdesenvolvidos, considerando a expansão e a redefinição do circuito inferior no período atual. Fazemos isso devido a nossos interesses de pesquisa, no presente momento, estarem voltados para essa reflexão. Contudo, temos também consciência de que é importante atentarmos para a análise de circuitos espaciais de produção, sejam eles superiores ou inferiores, sempre buscando a compreensão do espaço geográfico como "espaço banal”.

\section{O ESPAÇO BANAL DA CIDADE DOS PAÍSES SUBDESENVOLVIDOS: discussões sobre a expansão e a redefinição do circuito inferior no período atual}

Pensando o espaço geográfico como um espaço banal, especificamente o espaço da cidade dos países subdesenvolvidos, Santos (1979) formulou a teoria dos dois circuitos da economia urbana (circuito superior e circuito inferior) visando apreender a totalidade da dinâmica da socioeconomia urbana desses países. Segundo essa teoria, a cidade dos países subdesenvolvidos é um espaço banal, pois nela tudo e todos têm ou buscam seu lugar. Santos (1965) declara que essa cidade é marcada tanto pelas benesses da modernização - como as formas de conforto hodierno - quanto pela pobreza, pela desorganização e pela insuficiência dos serviços públicos, que também são elementos decorrentes da modernização econômica.

A cidade é sinônimo de espaço banal porque se apresenta como um rendilhado de verticalidades e horizontalidades (SILVEIRA, 2007a), um meio construído marcado por divisões do trabalho superpostas (SANTOS; SILVEIRA, 2001) como também por tempos rápidos e hegemônicos e por tempos lentos e não hegemônicos (Ibid.). Assim sendo, a cidade é compreendida como uma totalidade, um grande mercado, onde todas as atividades (tanto as do circuito superior como as do circuito inferior) e todos os agentes sociais (hegemônicos e não hegemônicos) se fazem presentes, exibindo diferentes modos de produzir o espaço (SILVEIRA, 2007a, 2004).

De acordo com Santos (1990), a cidade dos países subdesenvolvidos é una, porém segmentada, devido a ser permeada pela existência simultânea de diferentes, mas complementares, circuitos 
socioeconômicos, a saber: o circuito superior, que tem uma face marginal (BICUDO JÚNIOR, 2006), e o circuito inferior. Essa é, aliás, uma particularidade dessa cidade, a qual, de acordo com Santos (2008d), deve ser analisada tomando-se como fundamento sua realidade, sua história, e não princípios e/ou dados estabelecidos para o estudo da cidade dos países desenvolvidos, que têm outra realidade, outra história. Ao estudarmos a cidade dos países subdesenvolvidos tomando como fundamento sua própria história, evitamos correr intensivamente o risco de direcionarmos nossa pesquisa para um lado quando a realidade aponta para outro (SANTOS, 2008b).

Outras particularidades da cidade dos países subdesenvolvidos são apresentadas por Santos (2008d, 1978), a saber: enormes diferenças de renda e de acesso a bens e serviços entre os habitantes; tendência à hierarquização das atividades econômicas, com destaque dado, pelas autoridades políticas, às atividades desencadeadas por agentes hegemônicos que integram o circuito superior; e participação ativa dos pobres no mercado produtivo e de serviços, por meio de atividades do circuito inferior, o que impede que esses agentes sociais sejam tidos como afuncionais e/ou inertes.

Em decorrência dessas e de outras particularidades da cidade dos países subdesenvolvidos, Santos (2008d) considera um erro buscar compreendê-la a partir de concepções exteriores, formuladas diante de realidades que não condizem com determinados fatos que marcam essa cidade. Por isso, tomamos como principal alicerce teórico de nossas reflexões as concepções da teoria dos dois circuitos da economia urbana dos países subdesenvolvidos, a qual nos possibilita entender a cidade em que vivemos a partir de nossa realidade, isto é, a partir do subdesenvolvimento. Em outras palavras, uma teoria elaborada no âmbito da geografia brasileira, que nos oferece subsídios para a compreensão de nossa realidade, sob uma perspectiva crítica.

Apesar de Santos $(1979,2008 d)$ trazer à baila uma proposta teórica muito pertinente para o trabalho dos geógrafos dos países subdesenvolvidos, sobretudo dos que se atêm ao estudo das cidades em que vivem, frisamos que essa proposta ainda não vem sendo alvo de muitas reflexões no âmbito da Geografia, especificamente no Brasil. É verdade que, nos últimos anos, alguns geógrafos vêm procurando aplicá-la em seus estudos (MONTENEGRO, 2006, 2009; SILVA, 2008; SILVEIRA, 2004, 2007a, 2007b, 2009; REOLON; SOUZA, 2005; SPOSITO, 1983, 1999; PEREIRA, 2008; SILVA, 2009; OLIVEIRA, 2008, 2010; SILVA; AGUIAR, 2003; SILVA; HOLANDA, 2009; SILVA; BARBOSA, 2004), contudo o interesse por ela é ainda muito pequeno, sobretudo quando comparado à extensa produção que existe na geografia brasileira sobre a dinâmica da cidade.

Há geógrafos que afirmam não trabalhar com a citada teoria devido a ela ser estruturalista e, assim, compartimentalizar a realidade da cidade numa perspectiva dual (DANTAS, 1997). Tal concepção é equivocada, pois a teoria dos dois circuitos não explicita dualismo, mas, sim segmentação, tratando a cidade dos países subdesenvolvidos como única, porém marcada por desigualdades, contradições e combinações que trazem à baila o circuito superior e o circuito inferior, os quais, vale asseverar, se complementam, numa relação em que aquele subordina este.

Todavia, acreditamos que a grande maioria dos geógrafos não lança mão da teoria dos dois circuitos em suas análises por pura negligência, desvalorizando uma concepção teórica que, muitas vezes, nem conhece, pelo simples fato de ter, acreditamos, pré-conceito sobre ela. Ao negligenciarem essa teoria, esses geógrafos acabam desenvolvendo análises sobre a cidade dos países subdesenvolvidos alicerçados em realidades externas, que, geralmente, não condizem com o que é vivenciado nessa cidade. Em suma, acabam realizando análises esquizofrênicas da cidade, negligenciando, muitas vezes, grande parte das atividades socioeconômicas desenvolvidas nela.

Dito isso, ratificamos o fato de a cidade dos países subdesenvolvidos ser una, ou seja, marcada por uma lógica, a capitalista, e não por várias lógicas dissociadas umas das outras. Todavia, essa cidade também é segmentada, perpassada por seletividade espacial, o que nos impede de vê-la como uma máquina maciça e homogênea (SANTOS, 2008d). A segmentação do espaço urbano dos países subdesenvolvidos levou Santos $(1978,1979)$ a formular a teoria dos dois circuitos da economia urbana, a qual explicita que, nesses países, a cidade é constituída por dois subsistemas, que se complementam, de maneira contraditória, formando uma só estrutura. 
Com base nos ensinamentos de Santos (2008d), destacamos que o circuito superior origina-se - e reproduz-se - diretamente da modernização econômica, e que o essencial de suas relações ocorre em âmbitos que extrapolam o da cidade ou da região que o abrigam. Já o circuito inferior é formado por atividades de pequena dimensão, que, geralmente, são bastante enraizadas na escala do local, mantendo, assim, relações privilegiadas com a cidade ou a região em que estão.

O circuito inferior vem se apresentando como um abrigo para os pobres, que são submetidos aos interesses dos agentes do circuito superior. É por meio das pequenas atividades, sem garantias trabalhistas e grandes ganhos, que os pobres, os quais são a maioria da população brasileira (MONTEIRO, 2003; SAWAYA et al., 2003), vêm obtendo sua renda e a possibilidade de consumir no mundo capitalista. Essa característica de abrigo do circuito inferior leva Montenegro (2009) a enfatizar a importância desse circuito na compreensão atual da realidade urbana dos países subdesenvolvidos.

No tocante ao estado Rio Grande do Norte, o circuito inferior, seguindo a perspectiva nacional, também vem abrigando a maioria dos trabalhadores, que desempenham variadas atividades, em grande parte de pequeno porte, sem garantias trabalhistas e significativas remunerações. Assim sendo, destacamos, juntamente com Clementino, Silva e Pereira (2007) e Silva e Gomes (2007), o processo de precarização do mercado de trabalho que está em curso no Rio Grande do Norte, com a crescente substituição do "emprego com garantias" pelo "emprego flexível, ou sem garantias". Também está em curso, no território potiguar, um processo de expansão do circuito inferior, que ocupa cada vez mais pessoas e espaço, participando, assim, de maneira relevante da dinâmica do território potiguar no período da globalização.

Mas por que cada vez mais pessoas buscam o circuito inferior como um abrigo para a obtenção de sua sobrevivência? A resposta para esse questionamento vem do modelo de modernização econômica adotado pelos países subdesenvolvidos, calcado em altos coeficientes de capital e baixíssimos coeficientes de emprego (SANTOS, 2008d). À medida que a modernização se expande, aumentam as inovações tecnológicas, o conforto hodierno e a velocidade das transformações. Contudo, aumenta também a exploração do trabalho e as taxas de desemprego. No contexto dessa modernização, o circuito superior desabriga cada vez mais os trabalhadores, sobretudo os pobres, sem muita qualificação profissional.

Todavia, Santos (1978) já havia percebido que os desabrigados pelo circuito superior não estão perdidos no mercado de trabalho das cidades dos países subdesenvolvidos. Esses indivíduos desenvolvem atividades que não se alicerçam em grandes quantidades de capital, mas, sim, ao contrário, em pequenos estoques de mercadorias, em preços flexíveis, na movimentação intensa de dinheiro líquido etc. Por meio dessas atividades, repudiadas pelos agentes hegemônicos, que representam os interesses do circuito superior, a maioria da população dessas cidades sobrevive e expõe contrarracionalidades à racionalidade capitalista (SANTOS, 1996). Por isso, o circuito inferior decorre também da modernização econômica, mesmo que indiretamente (SANTOS, 2008d). Devemos ter em mente que o circuito inferior só existe porque há o circuito superior (que é o resultado direto da modernização), o qual é gerador de desemprego e de tantas outras precariedades sociais.

Santos (1979), em um contexto pretérito, elencou características típicas da organização do circuito inferior, no tocante a emprego e trabalho, crédito, preços de mercadorias, publicidade e reutilização de bens. Citamos agora essas características, de maneira pontual e sucinta:

- Nesse circuito, o emprego raramente é permanente. É acordado, geralmente, por meio de um contrato pessoal entre patrão e empregado, sendo a remuneração baixa, por vezes abaixo do mínimo vital. Há grande destaque para o trabalho familiar e autônomo. Por atividade, o número de pessoas ocupadas é baixo, mas, no geral, diante da grande quantidade de pequenos estabelecimentos comerciais e/ou de prestação de serviços, o número de pessoas ocupadas nesse circuito é considerável (SANTOS, 1979). 
- No circuito inferior, o trabalho é intenso, sendo os capitais reduzidos e a organização burocrática dispensável. As jornadas de trabalho são longas e flexíveis, principalmente quando a atividade funciona conjugada à casa do agente desencadeador. Nesse caso, o atendimento aos clientes pode dar-se em qualquer horário, inclusive de madrugada, dependendo das necessidades destes (Ibid.).

- Nesse circuito, o crédito é pessoal e direto. O objetivo, a partir desse crédito, é a busca desenfreada por dinheiro líquido, para saldar dívidas e, assim, manter o abastecimento de mercadorias para a atividade (Ibid.).

- Os preços das mercadorias não são fixos, valendo a pechincha. Assim sendo, a oscilação de preços é constante, seguindo os interesses dos clientes e o contexto em que a atividade está sendo realizada. A não rigidez dos preços, no circuito inferior, liga-se ao principal objetivo das atividades, que é assegurar a sobrevivência cotidiana dos agentes desencadeadores e das famílias destes, e não acumular capital de modo veemente (Ibid.).

- No circuito inferior, a publicidade não é necessária, graças ao contato direto que há com a clientela. Além disso, torna-se difícil fazer publicidade, devido ao fato de a margem de lucro ser pequena e ir diretamente para a sobrevivência do agente desencadeador da atividade e a de sua família (Ibid.).

- Nesse circuito, a reutilização de bens de consumo duráveis, como roupas, aparelhos eletrônicos e carros, é uma importante base para o estabelecimento e o funcionamento significativo das atividades (Ibid.).

No período atual, algumas dessas características continuam condizentes com a realidade, como as referentes ao emprego e ao trabalho bem como à reutilização de bens de consumo duráveis. Porém, há também algumas das características do circuito inferior, destacadas por Santos (1979), que vêm sendo alteradas, o que é extremamente normal diante das novas variáveis (informação, publicidade, finanças, consumo) determinantes e dominantes no período atual da globalização, as quais, cada vez mais, vêm se fazendo presentes em atividades do circuito inferior.

Tomando como fundamento as concepções de Silveira (2007a, 2004), afirmamos que as técnicas contemporâneas são flexíveis, divisíveis e dóceis, e, desse modo, são acessíveis ao uso pelos diferentes agentes sociais, sejam eles hegemônicos e qualificados profissionalmente ou não hegemônicos e sem grande ou nenhuma qualificação. Dessa maneira, técnicas modernas vêm sendo reutilizadas crescentemente no circuito inferior, fazendo com que novos serviços sejam oferecidos aos clientes, como os de publicidade, de informática, de telefonia móvel etc. (SILVEIRA, 2004).

Montenegro (2009) ressalta que técnicas de informação vêm sendo integradas às atividades do circuito inferior ora como instrumento de trabalho, ora como objeto de consumo ou de comercialização. Várias delas são também técnicas de circulação (como carros e/ou motos com alto-falantes para fazer a publicidade da atividade, sendo utilizados também para realizar a entrega de mercadorias comercializadas), o que faz com que o circuito inferior não permaneça hoje tão enraizado na escala do local, como ocorria anteriormente, ultrapassando, muitas vezes, as fronteiras da cidade onde se localiza e, assim, negociando com agentes de outros âmbitos territoriais.

Por vezes, o uso de técnicas de informação em atividades do circuito inferior revela o fato de hoje ele ser constituído por serviços de publicidade. Há vários agentes desse circuito que fazem publicidade de suas atividades por meio de carros e/ou motos de som, de rádios locais, de cartazes ou banners, de blogs na Internet etc. Outrossim, também há atividades do circuito inferior que negociam a realização de publicidade, adequando seus preços à realidade financeira da maioria dos agentes do referido circuito, o que leva à contratação de seus serviços para a propagação de pequenos comércios e/ou prestadores de serviços. Sendo assim, vemos que, no momento atual, a 
publicidade se faz presente em atividades do circuito inferior, inclusive como serviço a ser prestado (MONTENEGRO, 2009). O progressivo uso desse serviço em atividades do circuito inferior integra um processo de expansão do consumo, no período atual (SANTOS, 2007, 2008b), inclusive no tocante às classes mais pobres (SILVEIRA, 2004, 2009). A expansão do consumo vem ocorrendo relacionada ao processo de financeirização do território nacional (CONTEL, 2006).

A propagação da variável "finanças" no território brasileiro vem atendendo, sobretudo, os interesses hegemônicos dos agentes do circuito superior. O crédito financeiro, elemento comandado pelos agentes dominantes do capitalismo, vem sendo desburocratizado e oferecido aos diversos agentes sociais das variadas classes, por instituições bancárias e não bancárias (SILVEIRA, 2009).

Nessa perspectiva, já podem ser encontradas atividades do circuito inferior que oferecem a seus clientes crédito financeiro como uma forma de pagamento. Assim, eles têm a possibilidade de pagar por suas compras, ou pelo serviço que lhes é prestado, com cartão de crédito, podendo, inclusive, parcelar o valor a ser pago. Isso faz com que, muitas vezes, os preços, no circuito inferior, se tornem fixos, diante das "facilidades" oferecidas aos clientes para o pagamento.

Vale, ainda, frisar, de acordo com Silveira (2009), que, no contexto de financeirização do território nacional, o circuito superior se fortalece, enquanto o inferior vê o fosso existente entre ele e o superior aumentar. Os pobres vêm sendo alvo de campanhas publicitárias, desencadeadas por empresas do circuito superior, que lhes oferecem empréstimos, planos odontológicos, seguros pessoais e compra parcelada de produtos a altíssimos juros mensais, mas sem complicações burocráticas, o que conduz vários desses agentes a graves situações de endividamento e inadimplência. Além disso, por vezes, agentes do circuito inferior, seduzidos por essas campanhas publicitárias, deixam de produzir e passam a apenas consumir no circuito superior, contribuindo, dessa maneira, para que este amplie suas "garras" sobre aquele na contemporaneidade (SILVEIRA, 2009).

Vemos, portanto, que, no período da globalização, o circuito inferior não só se expande, mas também se redefine, passando a ser marcado por variáveis-chave do sistema vigente. Como exemplo empírico (concreto) da expansão e da redefinição desse circuito no período atual, podemos tomar para reflexão o caso do território norte-rio-grandense.

A tendência atual, no mercado potiguar, é a precarização do emprego e a atomização dos estabelecimentos comerciais e/ou de prestação de serviços, seguindo a perspectiva da modernização econômica. Essa tendência revela a expansão do circuito inferior no território norte-rio-grandense, onde a maioria dos trabalhadores vem obtendo meios para sua sobrevivência e, assim, produzindo o espaço por meio do desenvolvimento de atividades de pequeno porte, que não necessitam intensivamente de capital para funcionar, mas, sim, de mão de obra e de fluxos, sobretudo, de pessoas, de mercadorias e de pequenas quantidades de capital. Silva e Gomes (2007) parecem concordar com essa proposição de expansão do circuito inferior, no momento em que declaram que o comércio e os serviços propagam-se por todo o território potiguar, no período atual, não se concentrando mais apenas em algumas áreas, como ocorria anteriormente.

Quando afirmamos que o circuito inferior vem se expandindo no Rio Grande do Norte, estamos também dizendo, nas entrelinhas, que a pobreza vem se amplificando nesse território, o que faz com que a maioria da população local sobreviva em precárias situações. Alguns dados podem ser mostrados para que se perceba, a priori, a precária situação a que é submetida a maioria dos trabalhadores potiguares: em 2002, a despesa per capita média mensal das famílias $40 \%$ mais pobres do Rio Grande do Norte era 12,2 vezes menor que a das famílias 10\% mais ricas do estado (IBGE, 2010); em 2003, 52,2\% da população potiguar podia ser considerada pobre (Ibid.); no mesmo ano, em $88 \%$ dos municípios norte-rio-grandenses mais da metade da população era pobre, sendo que, em dez desses municípios, mais de $70 \%$ da população era constituída por pobres (Ibid.). Essas estatísticas indicam a precária situação de vida da maioria dos potiguares e a existência de intensa desigualdade socioeconômica no território estadual. 
Os dados destacados nos remetem à ideia de Silveira $(2007 \mathrm{a}, 2004)$ de que a pobreza, no período atual, é estrutural, não podendo, desse modo, ser considerada uma excepcionalidade ou um fenômeno, mas, sim, um perverso dado do sistema vigente. Sendo assim, a resolução do problema da pobreza, que, para Santos (1978), é o verdadeiro problema a ser atacado por todos nós, envolve mudanças estruturais, isto é, transformações paradigmáticas rumo a outra globalização, que tenha como pilar fundamental o bem-estar coletivo (SANTOS, 2003).

Os dados qualitativos e os quantitativos explicitados sobre o Rio Grande do Norte indicam, portanto, que o circuito inferior se expande no contexto atual desse território, servindo de abrigo para a maioria dos trabalhadores obter sua renda e, assim, ter acesso ao consumo. Entretanto, esse circuito, além de se expandir, também se redefine nesse estado, no período contemporâneo, adaptando-se e, por vezes, resistindo às transformações impostas pelos agentes do circuito superior, que comandam as variáveis-chave do período e, desse modo, apresentam-se como hegemônicos.

Afirmamos que o circuito inferior vem se redefinindo no Rio Grande do Norte a partir de observações que fizemos em atividades desse circuito em cidades do referido estado, entre os meses de maio e agosto de 2011. Essa redefinição alicerça-se na (re)utilização, cada vez mais frequente, de técnicas modernas por parte de agentes do circuito inferior, o que faz com que esse circuito seja caracterizado hoje pelas variáveis "informação", "finanças" e "consumo", que são determinantes e dominantes na globalização (SILVEIRA, 2009, 2004).

A (re)utilização de técnicas modernas faz com que no momento atual do Rio Grande do Norte algumas atividades do circuito inferior sejam desencadeadas com a importante presença de computadores com acesso à Internet, o que permite a prestação de determinados serviços e a realização de publicidade da atividade desempenhada na rede mundial de computadores; de carros e/ou motos que servem para realizar o transporte e a entrega de mercadorias bem como para fazer publicidade da atividade na cidade em que ela é desenvolvida, ou mesmo em cidades próximas; e de máquinas interligadas ao sistema financeiro nacional, as quais possibilitam aos clientes o pagamento, parcelado ou não, de suas compras com cartão de crédito (figura 1). Além disso, novos serviços vêm sendo oferecidos no circuito inferior (figura 2), a partir da reutilização e do manuseio de determinadas técnicas modernas: o desbloqueio de celulares e de videogames, a manutenção de computadores e a recarga de cartuchos de impressão, a revelação de fotografias, a fabricação e a instalação de antenas receptoras de sinais de redes de televisão, de rádio, de Internet, de celulares etc.

Diante de todas as reflexões traçadas até aqui, resta-nos trazer à tona algumas considerações finais, ratificando a necessidade de se estudar a dinâmica socioespacial da cidade dos países subdesenvolvidos considerando a totalidade dessa dinâmica, isto é, atentando para a (co)existência do circuito superior e do circuito inferior. Para isso, é pertinente considerar a teoria dos dois circuitos da economia urbana, analisando a dinâmica desses circuitos de acordo com as variáveis-chave que marcam o contexto atual do capitalismo. 

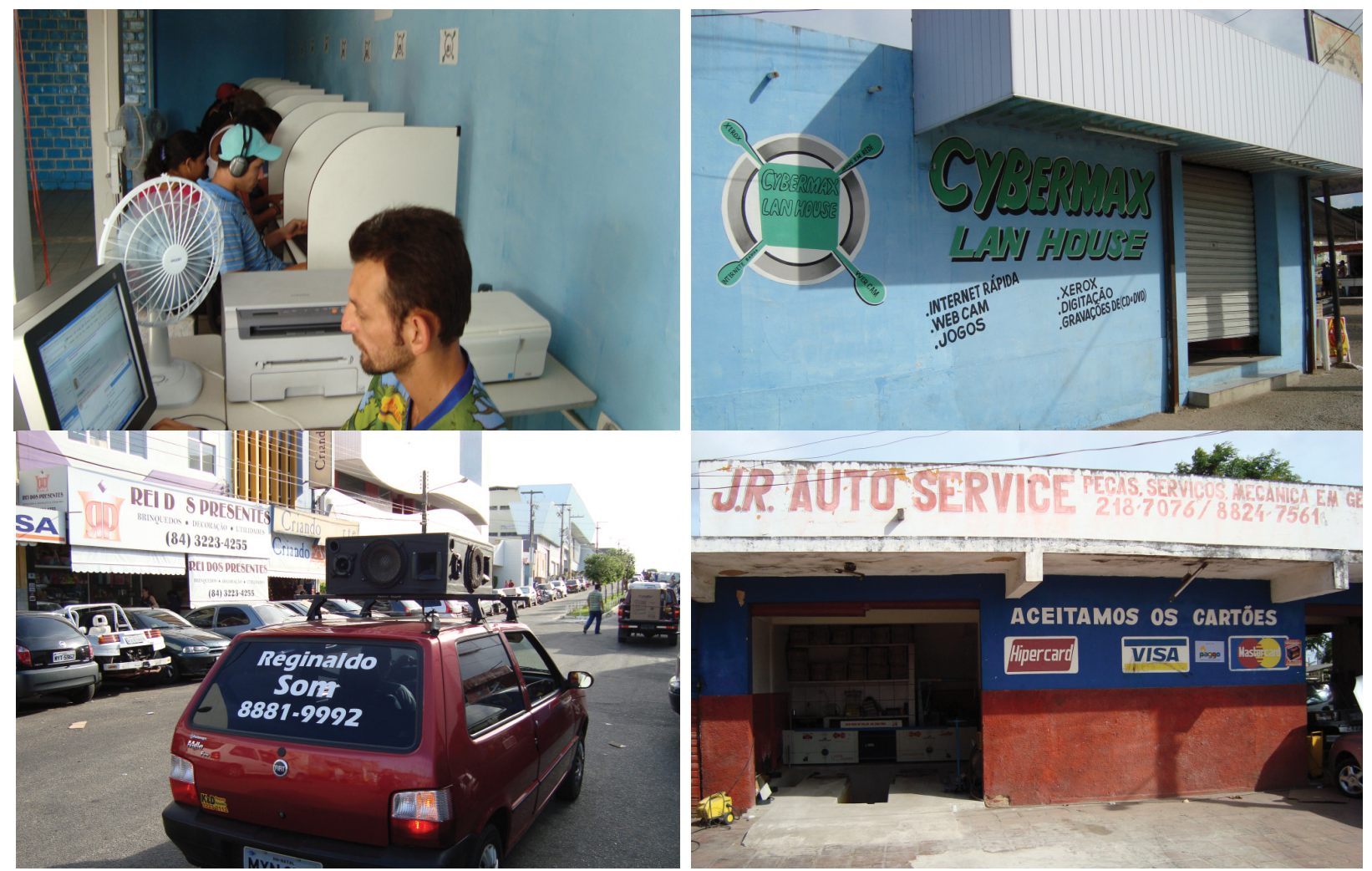

Figura 1 - Variáveis-chave (informação, publicidade e finanças) da globalização presentes em atividades do circuito inferior no Rio Grande do Norte Fonte: Pesquisa de campo, 2011.
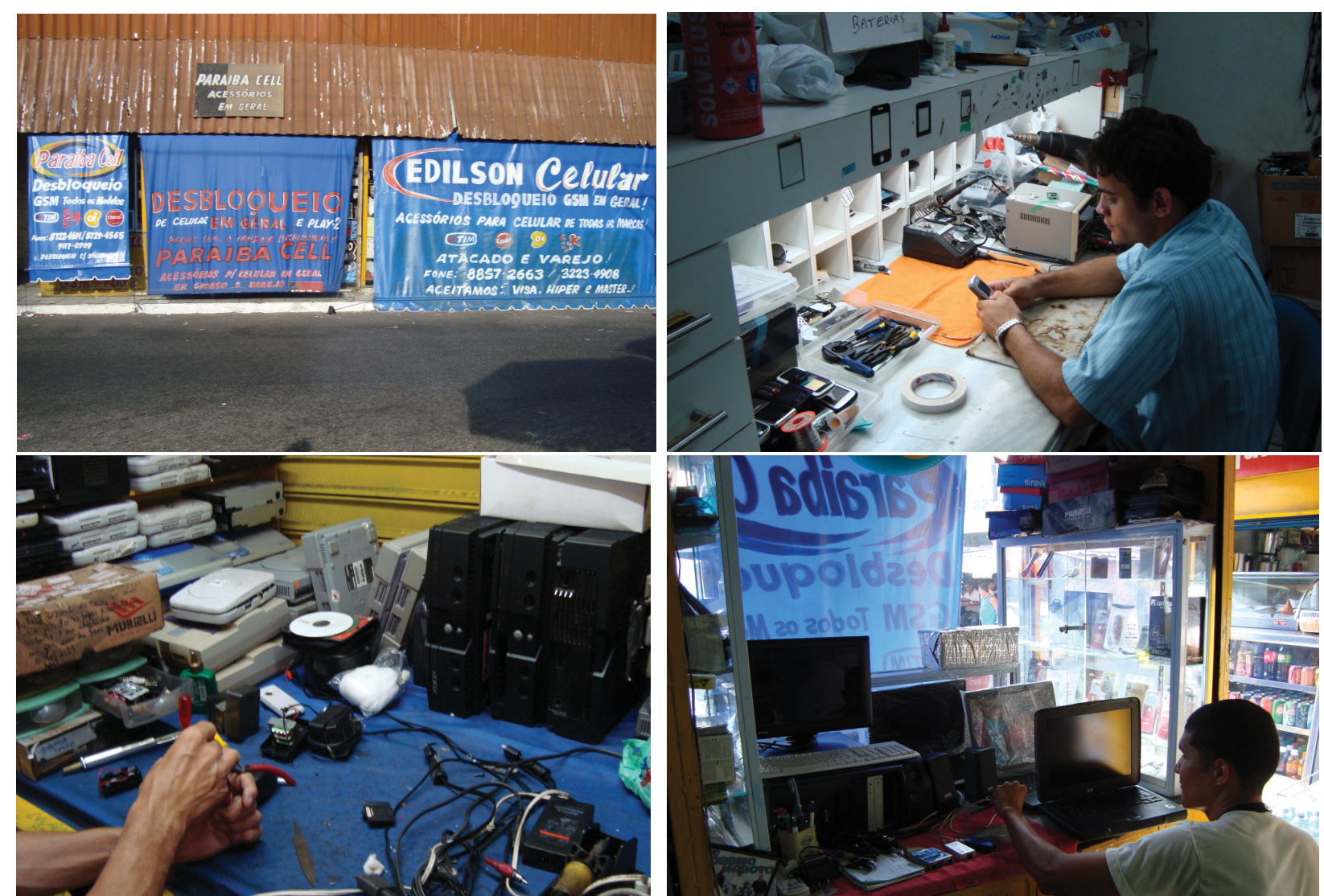

Figura 2 - Novas atividades (desbloqueio de celular, de vídeo game e manutenção de computador) desenvolvidas no circuito inferior no Rio Grande do Norte Fonte: Pesquisa de campo, 2011. 


\section{CONSIDERAÇÕES FINAIS}

Com as reflexões realizadas no desenvolvimento deste texto, chegamos a três considerações finais. Primeiro, a de que o espaço geográfico deve ser analisado em toda a sua complexidade, isto é, levando-se em conta todos os objetos e todas as ações que o caracterizam. Assim, é imprescindível atentar para o fato de hoje os objetos geográficos serem utilizados por todos os agentes sociais (hegemônicos e não hegemônicos), os quais agem na produção do espaço sob diferentes perspectivas: aqueles consideram o espaço como um recurso a ser explorado, calcando suas ações na geração intensa de lucratividades; já estes o consideram como um abrigo, buscando, predominantemente, sua sobrevivência frente à perversa realidade atual. $\mathrm{O}$ importante é termos consciência de que o espaço é produzido por todos os agentes sociais e por todas as atividades econômicas, sendo, portanto, banal. Destarte, o espaço que nos interessa, sobretudo a nós, geógrafos que vivemos nos países subdesenvolvidos, é o espaço em que coexistem todos os homens, todas as instituições e todas as empresas, enfim, o "espaço banal” (SANTOS, 1979, 1996, 1999).

Em segundo lugar, para analisarmos a dinâmica da cidade dos países subdesenvolvidos temos que considerar a história desse espaço, e não realidades externas, as quais, geralmente, não dão conta dessa dinâmica. Para tal análise, temos a nosso dispor a teoria dos dois circuitos da economia urbana (SANTOS, 1979), a qual nos explicita que a cidade dos países subdesenvolvidos é única, isto é, marcada somente, ou sobretudo, pelas premissas capitalistas, porém segmentada, ou seja, perpassada por desigualdades, contradições e combinações no tocante às ações dos agentes sociais e às atividades que estes desencadeiam. Essa cidade tem, portanto, em seu conteúdo, subsistemas (circuito superior e circuito inferior) que trazem à tona diferenças e desigualdades no tocante aos agentes sociais neles envolvidos, às tecnologias utilizadas e às maneiras como estas são utilizadas bem como às organizações (burocráticas ou não) colocadas em voga nas atividades desenvolvidas nos referidos subsistemas. Tais subsistemas se complementam numa relação em que o circuito superior cada vez mais subordina o inferior, formando um só sistema: o urbano, o da cidade dos países subdesenvolvidos. Portanto, ao contrário do que pensam alguns (DANTAS, 1997), a teoria dos dois circuitos não é estruturalista, nem mesmo dualista, mas, sim, uma proposta teórica que dá conta da complexidade da realidade da cidade para a qual voltamos nossas atenções, que, certamente, é "única", porém "segmentada".

Por fim, é premente buscarmos refletir sobre a dinâmica do sistema urbano das cidades dos países subdesenvolvidos de acordo com o contexto atual, isto é, considerando as características do circuito superior e as do circuito inferior. Para isso, temos que atentar para as variáveis-chave do atual processo de globalização (informação, publicidade, finanças, consumo), as quais marcam, mais e mais, as atividades do circuito superior e do circuito inferior, colocando em tela, desse modo, um contexto em que este se torna cada vez mais subordinado àquele, o que revela uma pobreza, agora, estrutural (SILVEIRA, 2004, 2007a, 2007b, 2009).

Esclarecemos que nosso anseio com a publicação do presente trabalho é despertar nos geógrafos dos países subdesenvolvidos a atenção para uma teoria que, embora importantíssima para a análise das cidades em que vivem, é, ainda hoje, pouco considerada por eles. É preciso deixar os pré-conceitos de lado e trabalhar a teoria dos dois circuitos da economia urbana de acordo com o período atual, seja para reconhecer sua importância, seja para criticá-la e propor sua superação, caso se tenha argumentos (teóricos e empíricos) pertinentes para isso. O imprescindível é não negligenciá-la, como vem sendo feito, desde a década de 1980, por parte da maioria dos geógrafos que voltam suas atenções para a cidade dos países subdesenvolvidos. Nesse sentido, fazemos nossas as palavras de Sposito (1999, p. 51): "como na obra O espaço dividido existem afirmações ainda atualizadas, é necessário ainda uma continuação desse debate para que a teoria seja esgotada [no sentido de estudada ou aplicada demasiadamente] ou superada [no sentido de aprofundada, renovada]". 


\section{REFERÊNCIA BIBLIOGRÁFICA}

ARANTES, L. ; AGUIAR, V. T. B. Juiz de Fora e os circuitos da economia urbana na era da informação. In: VIII SIMPÓSIO NACIONAL DE GEOGRAFIA URBANA, Anais... Recife: Univ. Federal de Pernambuco, 2003.

ARROYO, M. M. A economia invisível dos pequenos. Le Monde Diplomatique, ano 2, p. 30-31, 2008.

BICUDO JÚNIOR, E. C. O circuito superior marginal: produção de medicamentos e o território brasileiro. 2006. Dissertação (Mestrado em Geografia Humana) - Universidade de São Paulo, São Paulo.

CLEMENTINO, M. L. M. ; SILVA, M. G. ; PEREIRA, W. E. N. Estrutura produtiva e mercado de trabalho da Região Metropolitana de Natal. Natal: UFRN: Observatório das Metrópoles, 2007.

CONTEL, F. B. Território e finanças: técnicas, normas e topologias bancárias no Brasil. 2006. Tese (Doutorado em Geografia Humana) - Universidade de São Paulo, São Paulo.

DANTAS, E. W. C. A cidade e o comércio ambulante: o caso de Fortaleza em evidência. Revista do Departamento de Geografia (USP), São Paulo, n. 11, p. 187-210, 1997.

DE SOTO, H. El otro sendero: la revolución informal. Lima: Instituto Libertad y Democracia, 1992.

HARVEY, D. A produção capitalista do espaço. São Paulo: Annablume, 2005.

HARVEY, D. Espaços de esperança. São Paulo: Loyola, 2004.

INSTITUTO BRASILEIRO DE GEOGRAFIA E ESTATÍSTICA(IBGE). Sistema IBGE de Recuperação Automática (SIDRA): território - Rio Grande do Norte. Disponível em: $<$ http://www.sidra.ibge.gov.br/bda/ default.asp? $\mathrm{z}=\mathrm{t} \& \mathrm{o}=1 \& \mathrm{i}=\mathrm{P}>$. Acesso em: 08 nov. 2010.

MONTEIRO, C. A. A dimensão da pobreza, da desnutrição e da fome no Brasil. Estudos Avançados (USP), São Paulo, v. 17, n. 48, p. 07-20, maio/ago. 2003.

MONTENEGRO, M. R. Novos conteúdos da pobreza urbana no Brasil: o circuito inferior no período da globalização. In: 12DO ENCUENTRO DE GEOGRAFOS DE AMERICA LATINA: CAMINANDO EN UNA AMERICA LATINA EN TRANSFORMACIÓN, Anais... Montevidéu: Univ. Nacional do Uruguai, 2009.

MONTENEGRO, M. R. O circuito inferior da economia urbana na cidade de São Paulo no período da globalização. 2006. Dissertação (Mestrado em Geografia Humana) - Universidade de São Paulo, São Paulo. OLIVEIRA, E. L. Algumas considerações sobre o conceito de setor informal e a teoria dos circuitos da economia urbana. Geografias, Belo Horizonte, 04(1), p. 54-70, jan./jun. 2008.

OLIVEIRA, E. L. Circuito inferior da economia urbana e mídia impressa em Londrina/PR. In: XVI ENCONTRO NACIONAL DOS GEÓGRAFOS - CRISE, PRÁXIS E AUTONOMIA: ESPAÇOS DE RESISTÊNCIA E DE ESPERANÇAS, Anais... Porto Alegre: Universidade Federal do Rio Grande do Sul, 2010. PEREIRA, M. F. V. A pobreza urbana no Brasil: considerações a partir das análises geográficas. In: $5^{\text {a }}$ SEMANA ACADÊMICA DA UFU, Anais... Uberlândia: Universidade Federal de Uberlândia, 2008.

REOLON, C. A. ; SOUZA, V. A teoria dos dois circuitos da economia urbana de Milton Santos: subsídios para uma discussão. Formação, Presidente Prudente, n. 12, v. 02, p. 51-72, 2005.

SANTOS, M. ; SILVEIRA, M. L. O Brasil. Rio de Janeiro: Record, 2001.

SANTOS, M. A cidade nos países subdesenvolvidos. Rio de Janeiro: Civilização Brasileira, 1965.

SANTOS, M. A natureza do espaço. São Paulo: Editora da Universidade de São Paulo, 2008a.

SANTOS, M. A urbanização brasileira. São Paulo: Editora da Universidade de São Paulo, 2008b.

SANTOS, M. Da totalidade ao lugar. São Paulo: Editora da Universidade de São Paulo, 2008c.

SANTOS, M. Involução metropolitana e economia segmentada: o caso de São Paulo. In: RIBEIRO, A. C. T. ; MACHADO, D. B. P. (orgs.) Metropolização e rede urbana.. Rio de Janeiro: IPPUR/UFRJ, 1990. p. 79-113.

SANTOS, M. O espaço dividido: os dois circuitos da economia urbana dos países subdesenvolvidos. Tradução de Myrna T. Rego Viana. São Paulo: Editora da Universidade de São Paulo, 2008d.

SANTOS, M. O espaço dividido: os dois circuitos da economia urbana dos países subdesenvolvidos. Tradução de Myrna T. Rego Viana. Rio de Janeiro: Francisco Alves, 1979. 
SANTOS, M. O espaço do cidadão. São Paulo: Editora da Universidade de São Paulo, 2007.

SANTOS, M. O retorno do território. In: SANTOS, M. ; SOUZA, M. A. A. ; SILVEIRA, M. L. Território: globalização e fragmentação. São Paulo: Hucitec: ANPUR, 1996. p. 15-20.

SANTOS, M. O trabalho do geógrafo no Terceiro Mundo. Tradução de Sandra Lencione. São Paulo: Editora da Universidade de São Paulo, 2009.

SANTOS, M. Pobreza urbana. São Paulo, Recife: Hucitec: UFPE: Comissão Nacional de Regiões Metropolitanas e Política Urbana, 1978.

SANTOS, M. Por uma outra globalização. Rio de Janeiro: Record, 2003.

SAWAYA, A. L. Os dois brasis: quem são, onde estão e como vivem os pobres brasileiros. Estudos Avançados (USP), São Paulo, v. 17, n. 48, p. 21-44, maio/ago. 2003.

SILVA, A. B. ; GOMES, R. C. C. Dinâmica e organização do espaço metropolitana de Natal/RN: uma leitura a partir do setor terciário. In: IX COLOQUIO INTERNACIONAL DE GEOCRÍTICA: LOS PROBLEMAS DEL MUNDO ACTUAL. SOLUCIONES Y ALTERNATIVAS DESDE LA GEOGRAFÍA Y LAS CIENCIAS SOCIALES, Porto Alegre: UFRGS, 2007. p. 01-09.

SILVA, A. I. F. ; HOLANDA, V. C. C. Um estudo dos circuitos da economia urbana na cidade de Cariré-CE. Revista Homem, Espaço e Tempo, Universidade Estadual Vale do Acaraú - UVA, p. 52-70, março de 2009.

SILVA, J. S. ; BARBOSA, J. L. O sentido do trabalho informal na construção de alternativas socioeconômicas e o seu perfil no Rio de Janeiro. Disponível em: <www.iets.org.br/.../O_sentido_do_trabalho_informal_na_construcao_de_alternativas_socioeconomicas_e_o_seu_perfil_no_RJ.PDF $>$. Acesso em: 16 dez. 2004.

SILVA, S. C. O circuito inferior como elemento de integração dos territórios: o caso dos trabalhadores bolivianos no Brasil. In: I SIMPÓSIO NACIONAL DE GEOGRAFIA POLÍTICA - TERRITÓRIO E PODER, Anais... Curitiba: Universidade Federal do Paraná, 2009.

SILVA, V. P. Projeto de pesquisa "o circuito inferior e o meio construído de cidades pequenas do semi-árido potiguar na era da globalização: uma análise geográfica”. Natal: CEFET-RN, 2008.

SILVEIRA, M. L. Crises e paradoxos da cidade contemporânea: os circuitos da economia urbana. In: X SIMPURB: TRAJETÓRIAS DA GEOGRAFIA URBANA NO BRASIL: TRADIÇÕES E PERSPECTIVAS, Anais... Florianópolis: UFSC, 2007a.

SILVEIRA, M. L. Finanças, consumo e circuitos da economia urbana na cidade de São Paulo. Caderno CRH, Salvador, v. 22, n. 55, p. 65-76, jan./abr. 2009.

SILVEIRA, M. L. Globalización y circuitos de la economia urbana en ciudades brasileñas. Cuadernos Del Cendes, año 21, n. 57, tercera época, p. 01-21, sep./dic. 2004.

SILVEIRA, M. L. Metrópolis brasileñas: un análisis de los circuitos de la economía urbana. Revista Eure, v. XXXIII, n. 100, p. 149-164, Santiago de Chile, dic. 2007b.

SLATER, D. Capitalismo y desarrollo regional. CEDLA, Amsterdam, 22, 1982. p. 16-70

SOUZA, M. A. A. Cidade: lugar e geografia da existência. In: $5^{\circ}$ SIMPÓSIO NACIONAL DE GEOGRAFIA URBANA, Salvador: UFBA, 1997. p. 01-10.

SOUZA, M. A. A. O impacto da globalização e do ajuste econômico sobre o nível do emprego. In: SEMINÁRIO PLANO REAL E DESEMPREGO, São Paulo: Fundação Pedroso Horta, 1996. p. 01-05.

SOUZA, M. A. A. Política e território: a geografia das desigualdades. In: FÓRUM BRASIL EM QUESTÃO, Brasilia: UNB, 2002. p. 01-06.

SPOSITO, E. S. A teoria dos dois circuitos da economia urbana nos países subdesenvolvidos: seu esquecimento ou sua superação? Caderno Prudentino de Geografia, Presidente Prudente, n. 21, p. 43-51, 1999. SPOSITO, E. S. Migração e permanência das pessoas nas cidades pequenas. Os casos de Pirapozinho e Álvares Machado na Alta Sorocabana. 1983. Dissertação (Mestrado em Geografia Humana) - Universidade de São Paulo, São Paulo. 